Osteossarcoma parosteal: aspectos na radiologia convencional.

Autor: Francisco Nanci Neto.

Orientadores: Edson Marchiori, Alberto Domingues Vianna.

Dissertação de Mestrado. Rio de Janeiro: UFRJ, 2006.

Neste trabalho foi feito um estudo retrospectivo dos exames de 26 pacientes com osteossarcoma parosteal, provenientes do arquivo do Clube do Osso, Rio de Janeiro, e realizada a análise dos principais achados clínicos e aspectos radiológicos.

A doença predominou em pacientes do sexo feminino e teve idade média de acometimento na terceira década de vida. Os achados clínicos mais freqüentes foram o aumento do volume no local do tumor ( $77 \%$ dos casos) e a dor local (68\% dos casos). O local mais comum do tumor foi o oco poplíteo com $40 \%$ dos casos, e houve envolvimento metafisário em $92 \%$ dos tumores. 0 aspecto radiológico mais comumente encontrado foi de lesão bem mineralizada e intimamente justaposta à superfície óssea, com o córtex adjacente irregularmente espessado (92,3\% dos casos), observandose área de adesão a este (88,5\% dos casos), além de margens tumorais lobuladas (50\% dos casos) ou irregulares (38,5\% dos casos). Evidenciou-se também uma linha radiolucente entre o tumor e o osso adjacente (48\% dos casos), um padrão de mineralização mais denso na base que na periferia ( $42,3 \%$ dos casos), e uma pequena ocorrência de reação periosteal (15,4\% dos casos).
Apesar de a tomografia computadorizada e a ressonância magnética serem importantes na identificação de alguns aspectos do osteossarcoma parosteal, a radiologia convencional é altamente sugestiva deste tumor e permite, na maior parte dos casos, o diagnóstico diferencial com outras lesões da superfície óssea.

\section{Aspectos radiológicos e epidemiológicos do granuloma central de células gigantes.}

Autor: José Wilson Noleto Ramos Júnior.

Orientadores: Edson Marchiori, Renato Kobler Sampaio.

Dissertação de Mestrado. Rio de Janeiro: UFRJ, 2006.

Neste estudo foram avaliados, retrospectivamente, os aspectos epidemiológicos e radiológicos de 26 lesões de células gigantes (granulomas centrais de células gigantes e tumores marrons do hiperparatireoidismo) obsenadas em 22 pacientes, diagnosticadas e tratadas no Serviço de Cirurgia Buco-Maxilo-Facial do Hospital Universitário Pedro Ernesto - Universidade do Estado do Rio de Janeiro, no período compreendido entre janeiro de 1990 e junho de 2004.

Os prontuários, radiografias e laudos histopatológicos foram avaliados e revisados.

Os pacientes foram classificados em dois grupos. Os do grupo A, composto de 17 pacientes, não apresentavam evidências de hiperparatireoidismo, e os 5 do grupo B eram portadores de tal distúrbio. 0 sexo feminino $(72,7 \%)$ foi mais acometido do que o sexo masculino
$(27,3 \%)$. As lesões ocorreram com maior freqüência em pacientes da segunda e terceira décadas de vida, com média de idade de 27 anos. Dos três pacientes que apresentavam mais de uma lesão, um pertencia ao grupo $A$ e dois, ao B. A mandíbula (61,5\%) foi mais acometida do que a maxila $(38,5 \%)$. Na mandíbula, a região do corpo apresentou $75 \%$ das lesões, a anterior, 18,7\%, e a do ramo, 6,3\%. Na maxila, $60 \%$ das lesões ocorreram na região anterior e 40\%, na posterior. Radiograficamente, 57,7\% das lesões eram multiloculares e 42,3\%, uniloculares. Na mandíbula, $56,3 \%$ das imagens tinham aspecto multilocular e $43,7 \%$, uniloculares. Na maxila, as imagens multiloculares corresponderam a $60 \%$ e os $40 \%$ restantes eram uniloculares. Todas as 26 lesões diagnosticadas provocaram expansão de cortical óssea, sendo que 15,4\% produziram reabsorção das raízes dos dentes vizinhos, 50\% causaram deslocamento dentário e 11,5\% estavam relacionadas a sintomas dolorosos. $\mathrm{Na}$ mandíbula, 18,7\% das lesões cruzaram a linha média. Os pacientes que não apresentavam hiperparatireoidismo (grupo A) apresentaram $66,7 \%$ das lesões na mandíbula e 33,3\% na maxila, ao passo que os pacientes com tal distúrbio (grupo B) mostraram igualdade em relação à distribuição das lesões entre os arcos. 0 grupo A apresentou 66,7\% de lesões multiloculares e $33,3 \%$ de uniloculares. O grupo B apresentou $62,5 \%$ de lesões uniloculares e $37,5 \%$ de lesões multiloculares. Dos pacientes do grupo B, 80\% não apresentavam sinais e/ou sintomas de tal distúrbio, a não ser as lesões dos maxilares. 